\title{
Beyond Reflection to Being: \\ The Contemplative Practitioner
}

\author{
Susan M. Drake \\ Brock University \\ and \\ John P. Miller \\ OISE, Niagara Centre
}

Schon's book The Reflective Practitioner (1983) has facilitated much needed discourse in education about how teachers can reflect on their own practice. Schon argues that the best professional practice is based on reflection-in-action where the practitioner integrates theory and practice through tacit knowing. This concept of the reflective practitioner has encouraged educators to view teaching as more than mastery of content and technical competence. We believe that there is yet another level beyond the reflective practitioner that teachers can "live" in their practice; this is the level of Being. We call this educator the contemplative practitioner.

Schon (1983) claims that the professions have tended toward Technical Rationality. Education as simply the recall of knowledge and mastery of technique falls into this category. According to Schon, Technical Rationality is rooted in positivism which rests on the premise that empirical science provides the best model for all inquiry and practice. Thus empiricism has been used as the model not only for the sciences, but for the social sciences and even areas such as philosophy. One of the principal thrusts of 20th-century philosophy has been analytic philosophy that rests on positivistic assumptions and abandons metaphysics as nonsensical.

Technical Rationality involves instrumental problem solving and "depends on agreement about ends" (Schon, 1983, p. 41). To solve problems the person immersed in Technical Rationality usually relies on a model that often is not directly related to practice. Schein (1973) argues that there are three components for professional knowledge based on a positivistic framework that is hierarchic in nature. The basic science component is deemed to be the most important.

1. An underlying discipline or basic science component upon which practice rests or from which it is developed.

2. An applied science or "engineering" component from which many of the day-to-day diagnostic procedures and problem-solving solutions are derived. 
3. A skills and attitudinal component that concerns the actual performance of services to the client, using the underlying basic and applied knowledge. ( $p$. 43)

From the Technical Rationality perspective, the professions are viewed as applied sciences that are deemed to have less status than the pure sciences. For example, Greenwood (1966) argues that the scientific method is needed to bolster social work as a profession.

To generate valid theory that will provide a solid base for professional techniques requires the application of the scientific method to the service related problems of the profession. Continued employment of the scientific method is nurtured by and in turn reinforces the element of rationality. (p. 11)

From the Technical Rationality perspective, the professions are based on science from which the professional learns the more practical skills. These skills are viewed as having lesser status than the knowledge based on the scientific method.

Schon (1983) argues that Technical Rationality has not worked because abstract theory does not inform practice. Practitioners are confronted with problematic situations that are characterized by uncertainty, disorder, and indeterminacy. They can become uncomfortable when they cannot account for what they do according to theory. The effective practitioner, instead, operates more intuitively and makes changes based on moment-to-moment decisions. As Bernstein (1976) has written, the view of science from a Technical Rationality perspective is inadequate even at the theoretical level.

There is not a single major thesis advanced by either nineteenth-century Positivists or the Vienna Circle that has not been devastatingly criticized when measured by the Positivists' own stan-dards for philosophical argument. The original formulations of the analytic-synthetic dichotomy and the verifiability criterion of meaning have been abandoned. It has been effectively shown that Positivists' understanding of the natural sciences and the formal disciplines is grossly oversimplified. (p. 207)

Following Schon's argument, the technical approach to teaching has not been effective either. Teachers constantly find themselves in new situations without precedent. Erdman (1987) suggests that teaching by its very nature pushes educators into areas of ambiguity and uncertainty. From this perspective the technical approach to teaching is simply inadequate because it is not flexible enough.

\section{Reflection-in-action}

As an alternative to Technical Rationality, Schon (1983) presents his view of reflection which is a more artistic, intuitive process. Embedded in his conception of reflection is Polanyi's (1962) tacit knowing that involves an intuitive sense of how to do things that cannot always be explained in explicitly conceptual terms. Polanyi states "the aim of a skillful perfor- 
mance is achieved by the observance of a set of rules which are not known as such to the person following them" (p. 49). Reflection-in-action, then, refers to a skillful performance that tends to have the following qualities:

*There are actions, recognitions, and judgments which we know how to carry out spontaneously; we do not have to think about them prior to or during their performance.

*We are often unaware of having learned to do these things; we simply find ourselves doing them.

*In some cases, we were once aware of the understandings which were subsequently internalized in our feeling for the stuff of action. In other cases, we may never have been aware of them. In both cases, however, we are usually unable to describe the knowing which our action reveals. (p. 54)

Schon (1983) cites examples from baseball and music to explain his point. For example, the pitcher in baseball is constantly making adjustments to keep ahead of the hitters. He will change speeds and move the ball to different locations, and this process again tends to be intuitive rather than rational. In jazz, the players will improvise in a spontaneous way as they collectively develop a feel for the music and what combination of notes is appropriate at different moments. In teaching, the teacher will shift gears in the lesson plan to reach the student in that particular situation if he or she comes to a "teachable moment" based on an intuition of what is right.

Reflection-in-action can focus on a variety of elements. The practitioner, for example, may deal with the tacit norms underlying a particular decision, or on the appropriate strategy that is implicit in his or her behavior. Alternatively, the practitioner may reflect on the right feeling that can develop in approaching a problem, the way he or she has framed a problem, or on the appropriate role that he or she can play in solving the problem. In short, reflection-in-action weaves together practice and theory at an intuitive level.

The reflective practitioner may reframe the problem several times as the setting of the problem is probably more important than the problem solving procedures themselves. For example, Schon (1983) states that 80 to 85 percent of cases faced by an ophthalmologist do not fall into the "book" of standard diagnosis. The doctor must constantly look for new ways to diagnose and treat cases that come to him or her. Likewise, the teacher is always being confronted with new situations that require new solutions.

Schon (1983) quotes Tolstoy to give an example of reflection-in-action in education:

Every individual must in order to acquire the art of reading in the shortest possible time, be taught quite apart from any other and therefore there must be a separate method for each. That which forms an insuperable difficulty to one does not in the least keep back another, and vice versa. One 
pupil has a good memory and it is easier for him to memorize the syllables than to comprehend the vowellessness of the consonants; another reflects calmly and will comprehend a most rational sound method; another has a fine instinct, and he grasps the law of word combinations by reading whole words at a time.

The best teacher will be he who has at his tongue's end the explanation of what it is that is bothering the pupil. These explanations give the teacher the knowledge of the greatest possible number of methods, the ability of inventing new methods and above all, not a blind adherence to one method but the conviction that all methods are one-sided, and that the best method would be the one which would answer best to all the possible difficulties incurred by a pupil, that is, not a method but an art and talent....

Every teacher must ... by regarding every imperfection in the pupil's comprehension, not as a defect of the pupil, but as a defect of his own instruction, endeavor to develop in himself the ability of discovering new methods. (pp. 65-66)

In a sense the teacher is an on-the-spot researcher who must be ready with new methods based on an intuitive sense of what is appropriate for the student he or she is dealing with. As a result of this notion, researchers at the Massachusetts Institute of Technology have undertaken a program of inservice education for teachers based on the idea of reflection-in-action (Schon, 1983, p. 66). Educators (Holmes Group, 1990; Fullan \& Connelly, 1987) are advocating teacher reform based on the concept of the reflective practitioner.

\section{Being and Contemplation}

But is reflection enough? We would argue that there is an element that is necessary to good practice that is not included in the notion of reflection. This is the quality of Being. Perhaps the best example of Being comes from music, as it is not enough for a pianist just to be a good technician or even to play the music with the right intuitive sense. In listening to music we look for more than technique and musicianship; we also seek to be moved, and it is the musician's depth of character or Being that raises the performance to that level. Certainly what draws us to a Horowitz or Ashkenazy performance is not just the technical proficiency, but the depth and warmth of the performance.

Good teachers also evoke this quality of depth which Emerson (1965) so aptly captures in a talk to teachers:

According to the depth from which you draw your life, such is the depth not only of your strenuous effort, but of your manners and presence. The beautiful nature of the world has here blended your happiness with your power ... Consent yourself to be an organ of your highest thought, and lo! suddenly you put all men in your debt, and are the fountain of an energy that goes pulsing on with waves of benefit to the borders of society, to the circumference of things. (p. 437) 
Clearly we are talking about another level of experience that is beyond sense experience and even reflection. This third level adds to the holistic view of experience by connecting to Being. At this level, then, we also connect with a larger reality (e.g., the Tao, the Oversoul, the Ground of Being) that is much different than the empiricist's notion of an objective reality, or the conception of personal knowledge based on individual construction of meaning requiring commitment and reflection. This level, the contemplative practitioner, is realized through various forms of contemplation such as meditation, visualization, and myth which we discuss in the last half of this article.

Drawing on the thought of St. Bonaventure, a favorite philosopher of Western mystics, Wilber (1983) cites three levels of experience that correspond to the levels discussed in this paper: Technical Rationality, Reflection, and Being. Bonaventure describes three modes of knowing or three "eyes." The first eye is of the flesh where we perceive the external world of space, time, and objects. The second eye is reason where we know through philosophy, logic, and reflection. The third eye is that of contemplation where we gain knowledge of transcendent realities. At this level the distinction between subject and object disappears. Wilber notes:

Further, said St. Bonaventure, all knowledge is a type of illumination. There is exterior and inferior illumination (lumen exterius and lumen inferius), which lights the eye of flesh and gives us knowledge of sense objects. There is lumen interius, which lights the eye of reason and gives us knowledge of philosophical truths. And there is lumen superius, the light of transcendent Being which illumines the eye of contemplation and reveals salutary truth, "truth which is unto liberation." (p. 3)

Wilber (1983) also states that Bonaventure's three levels correspond with St. Victor (first of the great Victorine mystics) who distinguished between cogitatio, meditatio, and contemplatio. Cogitatio is empiricism and thus is based on knowing the facts of the external world. Meditatio involves internal reflection and seeking the truths of the mind. Contemplatio, again, is beyond duality "whereby the psyche or soul is united instantly with Godhead in transcendent insight (revealed by the eye of contemplation)" (p. 4).

Although Wilber (1983) has cited Christian mystics, these three eyes can be found in other mystical and philosophical traditions. For example, the Hindus also speak of a third eye which, again, is the eye of Being. Kant also spoke of three levels of knowing that correspond roughly to the levels cited above. Kant's three levels include: (a) sensibility-sense experience; (b) understanding-conceptual and scientific intelligence; and (c) reason which intuits transcendent ideas.

Wilber (1983) claims that the three levels are nested and each of three levels cited by Bonaventure and Hugh of St. Victor transcends the previous level. Thus the eye of the mind includes and transcends the eye of 
the flesh. The eye of mind includes sense experience but also contains the ideas, images, concepts, and logic. At this level we can reflect on our sense experience and use images and concepts to facilitate the reflection. Also, we can confine ourselves to the level of the mind in an area such as mathematics. However, it is an error to reduce the level of reason to the level of flesh. This kind of reductionism ignores the unique features of each level. Thus contemplation transcends, yet includes, the previous two levels.

Consider the relationship between practice and theory. From the Technical Rationality viewpoint, theory is seen as separate from and superior to practice. Yet teachers are often confused by a problematic situation where what they do does not fit the theory. Reflection-in-action solves this dilemma. Practice and theory are interwoven in a dialectical process of framing the problem and on-the-spot experimenting in a reflective conversation with the unique situation at hand. From the perspective of Being there is a synthesis of theory/practice and duality disappears; the teacher, acting from his or her center (i.e., Being) is connected with the student, content, and environment. Theory and practice are experienced as a unity.

Being has been called the Self (Jung), the Atman (Hunduism), our Buddha-nature (Buddhism), the soul (Christianity). Emerson (1909) wrote in his journal about this part of ourselves:

A man finds out that there is somewhat in him that knows more than he does. Then he comes presently to the curious question, Who's who? Which of these two is really me? the one that knows more or the one that knows less; the little fellow or the big fellow. (Vol. 9, p. 190)

Emerson's little fellow is the ego that so desperately strives to control and manipulate the universe to its own ends, while the big fellow (our Being) listens and is subject to a "vast and sudden enlargement of power." At this level the teacher lets go of the ego and reaches a fundamental harmony with his or her students.

Merton (1959), the American Trappist monk, spoke of the "inner self," which is another description of Being:

Instead of seeing the external world in its bewildering complexity, separateness, and multiplicity; instead of seeing objects as things to be manipulated for pleasure or profit; instead of placing ourselves over against objects in a posture of desire, defiance, suspicion, greed or fear, the inner self sees the world from a deeper and more spiritual viewpoint. In the language of Zen, it (the inner self) sees things "without affirmation or denial"; that is to say, from a higher vantage point, which is intuitive and concrete and which has no need to manipulate or distort reality by means of slanted concepts and judgments. It simply "sees" what it sees and does not take refuge behind a screen of conceptual prejudices and verbalistic distortions. (p. 17) 
Merton (1959) speaks of intuition as an aspect of Being, but is this the same intuition of Schon? Vaughn (1979) has spoken of levels of intuition, and three levels can be linked with Wilber's (1983) different eyes. The first level of intuition is what Vaughn calls a physical level where the body or the flesh reacts instinctively to a situation. For example, muscle tension can indicate stress in a person's life.

The next level is the mental which parallels the eye of reason. At the mental level intuition is often expressed through images, just as we may have flashes of insight that can lead to inquiry. This level is similar to Schon's (1983) reflective practitioner level where the individual uses moment-to-moment insight to help in the problem solving process.

The highest level of intuition in Vaughn's (1979) framework is the spiritual, which parallels the eye of contemplation. Here intuition is independent of feelings, thoughts, and sensations. Vaughn comments: "Paradoxically, the cues on which intuition depend on the other levels are regarded as interference at this level" (p. 77). At this level intuition moves beyond dualism to experience unity directly. The following statement by Teilhard de Chardin (1965) is an example of spiritual intuition.

The farther and more deeply we penetrate into matter, by means of increasingly powerful methods, the more we are confounded by the interdependence of its parts. Each element of the cosmos is positively woven from all the others ... It is impossible to cut into this network, to isolate a portion without it becoming frayed and unravelled at all its edges. All around us, as far as the eye can see, the universe holds together, and only one way of considering it is really possible, that is, to take it as a whole, in one piece. (pp. 43-44)

Phenomenologically, Being is experienced as unmediated awareness. This awareness is characterized by openness, a sense of relatedness and by awe and wonder. Greene (1987) talks about openness when she says,

we find ourselves thinking in front of the class with the end open, unresolved... There is something about open-endedness and even the uncertainty involved that enables us to reach out to our students, to communicate a kind of passion to them, no matter what we are teaching. (p. 12)

The sense of relatedness goes beyond Buber's I-Thou experience where there is still a "bipolar situation." When we experience Being, duality drops away, and as teachers we see part of ourselves in our students. At the deepest level we may experience brief moments of communion with our students. For example, Freedman (1990) describes how one teacher, Jessica Siegel, has each of her high school students write an autobiography, and through this process she develops a communal bond with each student.

Every year she finishes the autobiographies feeling the same way. Her students are heroes ... How they fill her with awe. How they, yes, inspire her ... 
When she reads their words, when she hears their voices, when she can practically grasp their urgent breath in this empty room, she knows her life has a reason. (pp. 68-69)

Teachers frequently can speak of how their students can instill in them a sense of wonder. For example, Marcia Umland (Macrorie, 1984), an elementary schoolteacher, states, "I get exhausted, but not burned out. Sometimes I'm dropping my dream for a day or two, but most days I'm on, and stunned by the kids" (p. 161). At this level we can see our students as Zen masters who with their directness can awaken us if we remain open. We need to keep the kind of openness suggested by Emerson (1966):

If a child happens to show that he knows any fact about astronomy, or planets, or birds, or rocks, or history that interests him and you, hush all the classes and encourage him to tell it so that all may hear. Then you have made your school-room like the world. Of course you will insist on modesty in the children and respect to their teachers, but if the boy stops you in your speech, cries out that you are wrong and sets you right, hug him! (pp. 226-227)

\section{The Contemplative Practitioner}

When we experience Being we tend to perceive quality in a more direct and open manner. Contemplation allows us to access Being and perceive reality in a new way. Buchman (1989) claims that contemplation includes "careful attention and quiet wonder" (p. 39). Buchman also cites Thomas Aquinas (1966) who believed that contemplation is more important than the active life in that the "return to the active life from the contemplative is by way of direction, in that the active life is guided by the contemplative."

How can educators become contemplative practitioners? In the remainder of this article we discuss various forms of contemplation and how these forms can be related to the act of teaching.

\section{Meditation}

One time-honored contemplative practice is meditation. Meditation has been practiced for centuries in different psychological and spiritual traditions. Kornfield (Miller, 1988), who teaches Buddhist insight meditation, states:

Most of us are disconnected; we are disconnected from our hearts and bodies, from the mind and its ways, from one another, from the earth and from the universal laws and truths. Through meditation we can reconnect with all of these factors. Through meditation we can rediscover love, oneness and freedom. Many people meditate for other reasons-for example to deal with pain and to understand suffering. However, if one practices with an open heart and mind, meditation eventually leads to a oneness, a deep connectedness. (p. 130) 
Meditation practice generally involves a quieting of the mind by focusing our attention on the in-out flow of the breath, counting our breaths or reciting a simple phrase (mantra). The task of meditation tends to be rather simple, so that we become attentive of what is happening both within and without. By quieting down we begin to gradually watch and gradually let go of the ego-chatter in our heads. It is the ego-chatter that forms the main barrier to our hearts, our Being. Ego-chatter can focus on such issues as how we can acquire material possessions, achieve a promotion, or control an interpersonal relationship. Traditionally, meditation practice usually allows us to see how the ego-chatter, or our thoughts, can control us. For example, during meditation the thought can arise that I need to buy that new jacket and instead of simply reacting to the thought we can simply watch the thought arise and disappear in our consciousness. Through meditation we learn that we can witness our thoughts rather than simply run on "automatic pilot" where we simply react unconsciously to our thoughts.

Is not meditation a form of reflection? The goal of meditation is to rest in that place that Merton (1959) referred to beyond thought and concept-a place of direct awareness. In the meditation process, the focus is not on analyzing or reflecting on the thoughts, but moving to a place of spacious awareness. In this place of direct awareness the world can break through our ego barriers so that we feel a deep connectedness to the environment that surrounds us.

If we are lost in our ego-chatter it is difficult for us to experience the world directly. Our thoughts and our ego form a barrier to the world and to our experience; through meditation we gradually dismantle the ego so that we see how things are. The ego is the source of our sense of separateness and thus by gradually letting go of ego we connect to others and the universe in a more direct and compassionate way. Deshimaru (1985), a Zen master, says: "Once the ego has disappeared there is no more duality. As soon as there is myself and others, that is duality. When there is no more me there are no more others; there is interdependence" (p. 19).

Griffin (1977) has described different levels of teaching. Two levels that he refers to are the ego level and the compassionate service level of consciousness. At the compassionate service level the teacher feels connected to his or her students.

You do not feel set off against them or competitive with them. You see yourself in students and them in you. You move easily, are more relaxed, and seem less threatening to students. You are less compulsive, less rigid in your thoughts and actions. You are not so tense. You do not seem to be in a grim win-or-lose contest when teaching. (p. 79)

At an ego level, teachers tend to relate to students on the basis of their own needs. When things do not turn out the way they expect, they can become jealous, frustrated, and resentful. Teachers become involved in an emotional struggle to maintain themselves in a particular way. 
Tremendous energy is exerted to maintain their view of how things should be, rather than relating openly to the situation as it arises. In contrast, meditation can be used simply to relax the body and mind before a difficult class. Teachers who practice meditation can find that things flow much more easily during the class. There is ample empirical evidence indicating the beneficial effects of meditation (Carrington, 1977).

As stated earlier, meditation is a method for moving beyond ego to a compassionate service level of consciousness. The late Trungpa (1984), a Tibetan meditation master, describes how meditation leads to an open heart and compassion:

When you slouch [in meditation], you are trying to hide your heart, trying to protect it by slumping over. But when you sit upright but relaxed in the posture of meditation, your heart is naked. Your entire being is exposedto yourself, first of all, but to others as well. So through the practice of sitting still and following your breath as it goes out and dissolves, you are connecting with your heart. (p. 45)

Through meditation we can develop sensitivity, a basic compassion, or what Trungpa calls the "awakened heart."

Meditation, however, should not be restricted to sitting practice; rather it can infuse one's existence with a basic sense of connectedness. The teacher who meditates, then, can bring the same attention and groundedness that develops in sitting practice to the classroom. This centeredness and attentiveness can be part of living presence in the classroom that students can respond to. For example, Waldorf education developed by Rudolf Steiner focuses on the development of the teacher's Being. Discussing Waldorf education, Richards (1980) claims that:

The inner development of the teacher acts upon the child's nature. The teachers feed the children through their own being. I have observed that the question of control, which so often comes up in discussions of dealing with the handicapped, is answered at Beaver Run by the way the children sense the presence of their teachers and seem little by little to be able to take a consequent form because of the quality of their being. (p. 134)

Noddings (1984), in her book Caring, writes:

The one caring is engrossed in the cared-for ... [This] means rather, that one-caring receives the other, for the interval of caring, completely and nonselectively. She is present to the other [the student] and places her motive power in his service. (p. 176)

There is evidence that meditation helps develop the presence and attentiveness that Noddings refers to. For example, Lesh (1970) found that meditation assisted counselors in the development of accurate empathy. Carrington's (1977) research supports the findings of Lesh; Carrington also argues that meditation would be a useful part of training and education in the helping professions. 
One of the authors has his students meditate as part of the courses he teaches. The students keep journals of their meditation experiences that provide, in a sense, a phenomenology of meditation practice. Students often begin the meditation experiencing a great deal of restlessness and sometimes resent that the instructor has made this a course requirement. For example, an early entry in one student's journal is "I found it difficult to relax and meditate tonight." After a few weeks most students settle down and begin to develop greater concentration and attention. They soon begin to notice changes in their own lives. One student comments: "I do feel though I am calmer, more philosophical about problems as they occur in my day. Things don't seem to build up to the point where I feel unable to cope for a short period." Sometimes a spouse or family member begins to notice changes. One student stated,

My wife has noticed a change in my behavior ... She pointed out that on the mornings when I meditate I leave for work 5-10 minutes later than my usual 7:30. This is not because I use the extra time for the actual meditation but because I "move slower" as I get ready.

Sometimes the students feel connected to other people in various settings. One student commented:

Sitting in church I was observing all the individuals who attend yet felt I was one separate form. All of us are very separate in appearance and identity but become one-through singing and prayer-and I observed myself as part of that.

Another student becomes almost poetic in his reflections:

My meditation created deep thoughts today.

Wholeness is really connectedness or interconnections.

Connectedness operates along the spatial, the temporal and the polarity axis. Each operate with their own mosaic of phenomena.

In global issues the main focus seems to be on the spatial communications network, the interconnectedness through an instantaneous network of interactions.

The temporal gets a lot less attention. But we must connect the past to the future. Only science and art venture into the network of the anticipation.

THE INNERCONNECTION OF inner conviction gets no attention at all or is avoided.

\section{Visualization}

Visualization, or guided imagery, offers another route toward Being. It involves focusing on images with the mind's eye; visualization is not only visual but also auditory, emotional, and muscular (Drake, 1989). Images are often the language of the unconscious and thus they allow us to access the unconscious mind. From this perspective, it has widely been used as a tool for personal and spiritual growth. 
The path to growth has two distinct but not separate dimensions (Firman \& Vargui, 1977). Personal growth involves the achievement of significant goals such as career success and is usually the focus of the first half of one's life. Spiritual, or transpersonal growth, involves finding meaning or purpose in life. It usually occurs during the second half of life where one can begin to find a deeper purpose in living. Firman and Vargui recommend that individuals synthesize the personal and spiritual dimensions, and imagery can be one contemplative vehicle to facilitate this process. In a study exploring how six teachers experienced visualization (Drake, 1989), individuals reported using imagery for both personal and spiritual growth. The personal growth level involved imaging an "ideal model" of successful performance. For example, visualizations included reaching peak performance in a marathon, teaching an effective lesson, and getting a desired job. Participants described the experience as one where they had control over concrete images of the physical world. All six teachers felt the imagery contributed to improved performance. This finding is supported by other studies (Samuels \& Samuels, 1975).

However, participants experienced different "layers" of visualization. The first was the conscious use of visualization to achieve important goals as described above. This would parallel the path to personal growth described by Firman and Vargui (1977). All six teachers also described another level that they experienced after the first level. They described this second level as one of self-awareness where an image was received spontaneously from the subconscious. They interpreted this as a message on how to live more fully and completely. For example, one woman did a daily visualization exercise where she focused on a current problem and worked with images as possible solutions to the problem. One person described this level as "self-awareness" or "self-therapy." All participants saw it as a route to growth.

Finally, three participants talked about a third level of visualization. At this level they had spontaneous images that had a numinous quality, and all three reported feeling connected through the imagery experience to a larger or "transcendent reality." At this level there was complete surrender to the imagery experience, a sense of becoming one with the image and an intuitive sense of being on the right track. These three individuals reported a sense of awe and wonder associated with visualization at this third level. This sense of awe and wonder seems inherent in contemplation (Buchman, 1989).

Interesting comparisons can be made with the levels of visualization experienced by teachers and the levels of knowing described in this article. For example, the first level of visualization is based on knowing from the external world and thus could parallel the Technical Rationality level. The second level of visualization is based on self-awareness and corresponds to the level of knowing involving internal reflection and 
understanding. Finally, the third level was experienced as contemplation since it was characterized by a sense of connectedness, awe, and wonder.

How can teachers integrate visualization into their work? They can consciously spend time practicing visualization. One interesting example comes from Waldorf education where teachers use visualization to connect with the inner life of the child. Richards (1980) writes:

Ideally, as part of their class preparation, the teachers strive to meditate upon their children individually. At night they call up an inner picture of each child, one by one, reenvisioning the way the child appeared during the day, how s/he walked, spoke, held his/her crayon, whether s/he was gaining or losing weight. The teachers review the day's relationship, concentrating on the child's higher being. They take this picture with them into sleep and again in the morning think afresh of the child. This inner preparation for meeting a class anew each day is said to be very important and fruitful for the children. (p. 109)

Teachers can also introduce visualizations into classroom settings. The six participants in Drake's (1989) study all used visualization in the classroom. Their objectives ranged from giving students more confidence, to goal attainment, to increasing creativity, to "making a kid aware he's a wonderful thing" (p. 228). For example, one teacher claimed that students experiencing visualization were "filled with wonder and awe mostly." Students, then, may be ready to be introduced to the contemplative realm.

\section{Narrative, Personal Mythology, Universal Mythology}

Universal myths provide another context for contemplation. They allow us to connect our personal stories to the Big Story that is described in various mythologies. The Big Story is essentially the story of how we overcome the prison of the ego to realize the fullness of our Being.

The path of transformation should be a "path with heart." In Campbell's (1988) words, the path with heart is "following one's bliss." The teacher, then, should be engaging in practice that makes him or her feel fully alive. Educators may look to a "pedagogy of bliss" that Wear (1990) describes as "a passionate engagement with something: the experience of awe and the experience of being connected with something greater than one's self" (p. 286). Making one's bliss explicit to students is a starting point to "awaken and nurture the kind of restless and reflective wonder" (p. 288) in students.

Teachers can turn to mythology to discover an age-old map to guide them on the inner journey. Their own life stories can be embedded in a larger, more universal story. This larger framework grants a wider perspective from which to interpret the story and allows an understanding of the path to Being.

Over the ages myths from different cultures have continued to have the same symbolism and structure. This universality in patterns suggests 
that myths tap into the very essence of being human. They appeal to humans by connecting with our Being and that still, small voice of the heart. A story that has been replayed again and again across many cultures is the journey of the hero. Campbell (1949) has labeled the journey the "monomyth" and outlined a skeleton plot that illustrates how the story unfolds in much the same way in many myths. It is the story of an individual called to adventure who undergoes a series of tests or trials as a part of that adventure. Eventually, the individual receives a reward, and he or she must return to the world with the fruits of the reward. The final step is to share newfound knowledge or serve others. The journey was taken by Jesus, Buddha, Moses, Dante, and many of the mythological heroes and heroines from most cultures. "But essentially, everyone's story is the same. It's the story of the hero's or heroine's journey" (Miller, 1988, p. 43).

The journey can be viewed metaphorically as a map of personal transformation (Campbell, 1988). The call to adventure means one must leave behind the world as one knows it. This stepping into the unknown is followed by a series of obstacles or trials that are usually self-created by ego attachments. As someone undergoes the tests there is illumination or learning from the suffering and pain. Ultimately, there is the reward, a personal transformation or change in identity as the individual has reached a new level of consciousness. Finally, one must return to the world with this new awareness.

Campbell (1949) suggests that it is possible to look at the lives of the great teachers metaphorically; that is, we can relate their journeys to our own experiences. For example, consider when the Buddha sat meditating under the Bodhi tree and he was tempted to break his concentration by Kama-Mara, the god of love and death.

The dangerous god appeared mounted on an elephant and carrying weapons in his thousand hands. He was surrounded by his army, which extended twelve leagues before him, twelve to the right, twelve to the left, and in the rear as far as to the confines of the world; it was nine leagues high. The protecting deities of the universe took flight, but the Future Buddha remained unmoved beneath the Tree. And the god then assailed him, seeking to break his concentration.

Whirlwind, rocks, thunder and flame, smoking weapons with keen edges, burning coals, hot ashes, boiling mud, blistering sands and fourfold darkness, the Antagonist hurled against the Savior, but the missiles were all transformed into celestial flowers and ointments by the power of Gautama's ten perfections. Mara then deployed his daughters, Desire, Pining and Lust, surrounded by voluptuous attendants, but the mind of the Great Being was not distracted. (p. 32)

Anyone who has tried to meditate can identify with difficulties that the Buddha faced since they represent in metaphoric terms the ego's attempts to interfere with our concentration. 
Educators can embed their own life stories in the universal mythologies. Graduate students of one of the authors are presented with this metaphorical map for transformation. Many choose to explore this further in their journals. Consider the journal of Brian who has just entered a Master of Teaching program. "The call was an internal one as my intellect began to gather evidence that the path I was following was not one with meaning." He applied and was accepted to graduate school. He was happy teaching elementary school but found it was just not enough. "Naturally, I did grieve for my old path, as it was comfortable, predictable and safe." As he begins this new journey: "For me it is a path of heart because it fulfills many of the values I hold true ... Only with my mind and eyes open to new ideas can I gain increased meaning, and with increased meaning realize my full potential." He describes beginning his new path: "Clearly, my demons and dragons are self-doubt, anxiety and uncertainty." Yet he plans for ways to overcome the obstacles of his ego as "having the degree in my hand and approaching the end of the journey, I hope I will see my capacities as a teacher expanded and stretched in ways I never thought possible." He expects "to gain meaning from my journey as well as a sense of accomplishment and delight." His service will be to share his newfound knowledge and the process of his journey with others.

The universality of myths allow us to move beyond just personal reflection to a more contemplative state. Myths are filled with images that act in the same synthesizing manner as visualization; in short, they allow us to connect conscious and unconscious experience. As well, when individuals embed their stories into the larger story, they then belong to a timeless community of those who have traveled the path of transformation (Larsen, 1990). In this way educators can truly experience an interconnection with others.

\section{Conclusion}

In reviewing the three levels of practice, it is possible to view them in terms of a nesting concept. The teacher must know the content of the subject matter. Second, a good teacher should be able to reflect-in-action so that he or she can relate to his or her work in the open, intuitive manner that Schon (1983) argues is necessary for good practice. Finally, the teacher can go beyond reflection to contemplation. It is at this level, embedded in subject competence and reflection, that the practitioners can connect with students at a deeper level. It is not a forced state but rather a natural place of caring and compassion. And it is from this place of the heart that students can connect to the ground of Being which in turn adds meaning and purpose to their lives.

\section{References}

Aquinas, T. (1966). Summa theologiae, Action and contemplation (Vol. 46) (J. Aumann, Ed.). New York: Blackfriars.

Bernstein, R.J. (1976). The restructuring of social and political theory. New York: Harcourt Brace Jovanovich. 
Buchman, M. (1989). The careful vision: How practical is contemplation in teaching? American Journal of Education, 78, 35-61.

Campbell, J. (1949). The hero with a thousand faces. Princeton, NJ: Princeton University Press.

Campbell, J. (1988). The power of myth. New York: Doubleday.

Carrington, P. (1977). Freedom in meditation. Garden City, NY: Anchor Press/Doubleday.

Crampton, M. (n.d.). Dialogic imaginal integration. London:

Deshimaru, T. (1985). Questions to a Zen master. New York: Dutton.

Drake, S. (1988). An exploration of the experience of visualization in teachers' lives and in their classrooms. Unpublished doctoral dissertation, University of Toronto.

Emerson, R.W. (1909). The journals of Ralph Waldo Emerson (E.W. Emerson \& W.E. Forbes, Eds.). New York: Houghton Mifflin.

Emerson, R.W. (1965). Selected writings. New York: New American Library.

Erdman, J. (1987). Reflecting on teaching and adult education. Lifelong Learning, 10(8), 19-22.

Firman, J., \& Vargui, J. (1977). Dimensions of growth. Synthesis, 3-4.

Freedman, S.G. (1990). Small victories: The real world of a teacher, her students and their high school. New York: Harper \& Row.

Fullan, M., \& Connelly, F. (1987). Teacher education in Ontario: Current practice and options for the future. Ottawa, ON: Ministry of Education.

Greene, M. (1987, Autumn). Sense making through story: An autobiographical inquiry. Teaching Education, 2, 9-14.

Greenwood, D. (1966). Attributes of a profession. In Vollmer \& Mills (Eds.), Professionalization. Englewood Cliffs, NJ: Prentice-Hall.

Griffin, R. (1977, February). Discipline: What's it taking out of you? Learning, 78-80.

Holmes Group. (1990). Tomorrow's schools: Principles for the design of professional development schools. East Lansing, MI: Author.

Larsen, S. (1990). The mythic imagination. New York: Bantam Books.

Lesh, T.V. (1970). Zen meditation and the development of empathy in counselors. Journal of Humanistic Psychology, 10, 39-74.

Macrorie, K. (1984). 20 teachers. New York: Oxford University Press.

Merton, T. (1959). The inner experience. Unpublished manuscript.

Miller, J.P. (1988). The holistic curriculum. Toronto, ON: OISE Press.

Miller, R. (1988). The quest for vision: An interview with Joseph Jastrab. Holistic Education Review, 1(3), 40-43.

Noddings, N. (1984). Caring. Berkeley, CA: University of California Press.

Polanyi. M. (1962). Personal knowledge: Towards a post-critical philosophy. Chicago: University of Chicago Press.

Richards, M.C. (1980). Toward wholeness: Rudolf Steiner education in America. Middletown, CT: Wesleyan University Press.

Samuels, M., \& Samuels, N. (1975). Seeing with the mind's eye: The history, techniques and uses of visualization. New York: Random House.

Schein, E. (1973). Professional education. New York: McGraw Hill.

Schon, D.A. (1983). The reflective practitioner: How professionals think in action. New York: Basic Books.

Teilhard de Chardin, P. (1965). The phenomenon of man. New York: Harper Torch Books.

Trungpa, C. (1984). Shambhala: The sacred path of the warrior. Boston, MA: Shambhala. Vaughn, F. (1979). Awakening intuition. Garden City, NJ: Anchor Books.

Wear, D. (1990). A pedagogy of bliss. Educational Forum, 54(3), 283-291.

Wilber, K. (1983). Eye to eye: The quest for the new paradigm. Garden City, NJ: Anchor Books. 